\title{
Effects of Copper Dopants on the Magnetic Property of Lightly Cu-Doped ZnO Nanocrystals
}

\author{
Zhi Wang ${ }^{1, *}$, Wenzhen Xiao ${ }^{1}$, Mengmeng Tian ${ }^{1}$, Neng Qin ${ }^{1}$, Haidong Shi ${ }^{1}$, Xiwei Zhang ${ }^{1}$, \\ Wenke Zha ${ }^{1}$, Jiahua Tao ${ }^{2}$ and Junlong Tian ${ }^{1}$ \\ 1 School of Physics and Electrical Engineering, Anyang Normal University, Anyang 455000, China; \\ 01564@aynu.edu.cn (W.X.); 01566@aynu.edu.cn (M.T.); 01551@aynu.edu.cn (N.Q.); \\ 02008@aynu.edu.cn (H.S.); zhangxw@aynu.edu.cn (X.Z.); science@hnu.edu.cn (W.Z.); tjl@aynu.edu.cn (J.T.) \\ 2 Key Laboratory of Polar Materials and Devices (MOE), East China Normal University, Shanghai 200241, \\ China; jhtao@phy.ecnu.edu.cn \\ * Correspondence: wz@aynu.edu.cn
}

Received: 21 July 2020; Accepted: 4 August 2020; Published: 11 August 2020

check for updates

\begin{abstract}
To explore the origin of magnetism, the effect of light $\mathrm{Cu}$-doping on ferromagnetic and photoluminescence properties of $\mathrm{ZnO}$ nanocrystals was investigated. These $\mathrm{Cu}$-doped $\mathrm{ZnO}$ nanocrystals were prepared using a facile solution method. The $\mathrm{Cu}^{2+}$ and $\mathrm{Cu}^{+}$ions were incorporated into $\mathrm{Zn}$ sites, as revealed by X-ray diffraction (XRD) and X-ray photoelectron spectroscopy (XPS). At the $\mathrm{Cu}$ concentration of 0.25 at. $\%$, the saturated magnetization reached the maximum and then decreased with increasing $\mathrm{Cu}$ concentration. With increasing $\mathrm{Cu}$ concentration, the photoluminescence (PL) spectroscopy indicated the distribution of $\mathrm{V}_{\mathrm{O}}^{+}$and $\mathrm{V}_{\mathrm{O}}^{++}$vacancies nearly unchanged. These results indicate that $\mathrm{Cu}$ ions can enhance the long-range ferromagnetic ordering at an ultralow concentration, but antiferromagnetic " $\mathrm{Cu}^{+}-\mathrm{Vo}_{\mathrm{O}} \mathrm{Cu}^{2+\prime}$ " couples may also be generated, even at a very low $\mathrm{Cu}$-doping concentration.
\end{abstract}

Keywords: diluted magnetic semiconductors; $\mathrm{Cu}$ doped $\mathrm{ZnO}$; photoluminescence; ferromagnetism

\section{Introduction}

The combination of logic semiconductors with the information storage capabilities of magnetic elements can be realized possibly in a single material through spintronic devices. Fortunately, room temperature ferromagnetism (RTFM) can often be observed in ZnO semiconductor material doped by transition metals (TM) [1,2]. Therefore, zinc oxide (ZnO) doped by 3d TM (e.g., Co [3], $\mathrm{Ni}$ [4], Mn [5,6], Cu [7], and Cr [8]) has been investigated extensively as a promising diluted magnetic semiconductor (DMS) for prospective applications in spintronic devices. However, the debates on the origin of ferromagnetic behavior and coupling mechanism are still open, which have been attributed to metal clusters, vacancy clusters [9,10], secondary oxide phases [11,12], and magnetic contamination [13].

$\mathrm{Cu}$-doped $\mathrm{ZnO}$ system has been given much attention due to two reasons given below. Firstly, the radius match-up of $\mathrm{Cu}$ and $\mathrm{Zn}$ ions can lead to a low formation energy. Secondly, neither metallic $\mathrm{Cu}$ nor copper oxides $\left(\mathrm{CuO}\right.$ and $\left.\mathrm{Cu}_{2} \mathrm{O}\right)$ are ferromagnetic [14]. For these reasons, there is an opportunity to clarify the origin and the coupling mechanism of ferromagnetic behavior of diluted magnetic semiconductors, which are still under debate [2,15]. Upon this, much effort has been devoted to investigating $\mathrm{Cu}$-doped $\mathrm{ZnO}$ systems. More recently, more meaningful phenomena were discovered upon $\mathrm{Cu}$-doped $\mathrm{ZnO}$. For example, Liu et al. reported that RT polarization-applied electric field (P-E) loops can be observed directly, demonstrating the existence of multiferroic properties of the $\mathrm{ZnO}: \mathrm{Cu}$ films [16]. Muhammad Younas found that the resistance can be switched from high 
resistance (HRS) to low resistance (LRS) through reversible tuning of the ferromagnetism of Cu-doped $\mathrm{ZnO}$ thin films [17]. These results have made $\mathrm{Cu}$-doped $\mathrm{ZnO}$ even more appealing to researchers.

However, there is no consensus on the origin of RTFM. Sharma et al. reported that RTFM of $\mathrm{Cu}$-doped $\mathrm{ZnO}$ nanorods decreased with increasing $\mathrm{Cu}$ concentration (1-5\%) [18], while Yildirım et al. found that RTFM increased [14]. The electronic structure of $\mathrm{Cu}$-doped $\mathrm{ZnO}$ has been calculated, indicating that the empty $\mathrm{Cu} 3 d$ states are located in the gap region without the hybridization with the $\mathrm{Zn} 4 \mathrm{~s}$ conduction band due to the strong $\mathrm{Cu}-\mathrm{O}$ covalency in $\mathrm{CuO}_{4}$ tetrahedron [19]. This would make the $\mathrm{Cu}$ solubility in $\mathrm{ZnO}$ very low ( $1 \%$ at most). It means that secondary oxides can be formed when the $\mathrm{Cu}$ doping level exceeds $1 \%$, and this has been verified experimentally [20]. Further, some results found that secondary oxides and its related structures of $\mathrm{Cu}$ dopants can also contribute to the RTFM [12,21], which is a discrepancy from that reported before [22]. Hou et al. found that porous $\mathrm{Cu}_{2} \mathrm{O}$ thin films manifest unexpectedly large RTFM, which was ascribed to coupling between oxygen vacancies and local magnetic moments [21]. Gao et al. reported that the RTFM of the CuO-ZnO system can be tuned by the interface counts for $\mathrm{CuO}$ and $\mathrm{ZnO}$ heterostructures [12]. Thus, it is necessary to lower the concentration of $\mathrm{Cu}$ dopants to prevent the generation of $\mathrm{Cu}$-related secondary phases, minimizing the effect of extrinsic sources on the RTFM.

Herein, we prepared a series of lightly $\mathrm{Cu}$-doped $\mathrm{ZnO}$ nanocrystals ( $1 \%$ at most) using a facile one-pot solution method. The ferromagnetic property was characterized by measuring the field-dependent magnetization $(\mathrm{M}-\mathrm{H})$ curves of these nanocrystals. The role of $\mathrm{Cu}$ dopants in the magnetic property of lightly $\mathrm{Cu}$-doped $\mathrm{ZnO}$ nanocrystals was investigated with the help of $\mathrm{X}$-ray diffraction (XRD), X-ray photoelectron spectroscopy (XPS), and photoluminescence (PL) spectroscopy. Our results suggest that $\mathrm{Cu}$ ions at an ultralow concentration can enhance the long-range ferromagnetic ordering but may generate the antiferromagnetic " $\mathrm{Cu}^{+}-\mathrm{Vo}_{-}-\mathrm{Cu}^{2+}$ " couples even at a very low $\mathrm{Cu}$ doping concentration.

\section{Experimental Section}

\subsection{Chemicals}

Zinc acetate dihydrate $\left(\mathrm{Zn}\left(\mathrm{OOCCH}_{3}\right)_{2} \cdot 2 \mathrm{H}_{2} \mathrm{O}\right)$, hexamethylenetetramine (HMTA), and copper acetate monohydrate $\left(\mathrm{Cu}\left(\mathrm{OOCCH}_{3}\right)_{2} \cdot \mathrm{H}_{2} \mathrm{O}\right)$ were purchased from Sigma-Aldrich Co. LLC. (Shanghai, China). All the chemicals are of spectrography grade or better and used without further purification.

\subsection{Preparation of Lightly $\mathrm{Cu}$-Doped $\mathrm{ZnO}$}

A serial of lightly $\mathrm{Cu}$-doped $\mathrm{ZnO}$ with various $\mathrm{Cu}$ concentrations were prepared by a facile solution method. In a typical synthesis procedure, stoichiometric $\mathrm{Zn}\left(\mathrm{OOCCH}_{3}\right)_{2} \cdot 2 \mathrm{H}_{2} \mathrm{O}$ and $\mathrm{Cu}\left(\mathrm{OOCCH}_{3}\right)_{2} \cdot \mathrm{H}_{2} \mathrm{O}$ (total up to $0.03 \mathrm{~mol}$ ) were dissolved in $300 \mathrm{~mL}$ deionized water as the precursor together with $0.03 \mathrm{~mol}$ HMTA. The mixture was ultrasonicated and stirred vigorously for $2 \mathrm{~h}$ in a beaker. Before growth, a glass substrate was placed in the beaker. The glass substrate was cleaned by a piranha solution for $10 \mathrm{~min}$ and followed by deionized water under ultrasonication [23]. Then, the mixture were sealed and kept at $95^{\circ} \mathrm{C}$ for $24 \mathrm{~h}$. After growth, the substrate was rinsed in deionized water thoroughly and dried in air at room temperature. The stoichiometric ratios of $\mathrm{Cu}\left(\mathrm{OOCCH}_{3}\right)_{2} \cdot \mathrm{H}_{2} \mathrm{O}$ to $\mathrm{Zn}\left(\mathrm{OOCCH}_{3}\right)_{2} \cdot 2 \mathrm{H}_{2} \mathrm{O}$ were set to $0,0.1 \%, 0.25 \%, 0.5 \%$, and $1 \%$, respectively.

\subsection{Characterizations}

$X$-ray diffractions of the samples were carried out using a Ni-filtered $\mathrm{Cu} \mathrm{K}_{\alpha}(\lambda=1.5418 \AA)$ radiation source (D/Max-2550 V, Rigaku Co., Tokyo, Japan). The XRD scans were collected from $30^{\circ}$ to $80^{\circ}(2 \Theta)$, with a step of $0.02^{\circ}$ and a data collection time of $0.5 \mathrm{~s}$. The JCPDS PDF database [24] was utilized for phase identification. All the products underwent scanning electron microscopy (SEM, JSM7500SF, JEOL, Japan) to compare the morphology of these samples. X-ray photoelectron spectroscopy (XPS) was conducted in an Axis Ultra DLD spectrometer using a monochromatized $\mathrm{Al} \mathrm{K}_{\alpha} \mathrm{X}$-ray source $(1486.6 \mathrm{eV})$ 
in order to monitor the binding state of the ions. Magnetic measurements were performed on a Superconducting Quantum Interference Device (SQUID, MPMS-2, Quantum Design Inc., San Diego, CA, USA). The samples were filled in a small container made of polyvinyl chloride, whose diamagnetic moment was subtracted from the measured magnetization values. The photoluminescence spectra were recorded at room temperature with a Jobin-Yvon LabRAM HR 800 UV micro-PL spectrometer using He-Cd (325 nm) laser as the excitation source.

\section{Results and Discussions}

Figure 1 presents the X-ray diffraction (XRD) $\theta-2 \theta$ scan of as-grown undoped $\mathrm{ZnO}$ and lightly $\mathrm{Cu}$-doped $\mathrm{ZnO}$ nanocrystals. All the diffraction peaks can be readily indexed as a hexagonal wurtzite $\mathrm{ZnO}$ structure (JCPDS card No. 36-1451) with space group P6 3 mc and lattice constants of $a=3.250 \AA$ and $c=5.207 \AA$. No other peaks corresponding to copper and its related secondary phases were detected within the detection limit of XRD. This reveals that the substitution of Cu dopants does not change the wurtzite structure. The inset in Figure 1 shows the magnified (101) peaks of XRD patterns. A tiny blue shift of the (101) peaks of these three lightly $\mathrm{Cu}$-doped $\mathrm{ZnO}$ nanocrystals can be discerned by comparing with the undoped $\mathrm{ZnO}$ sample, indicating that the lattice constants were enlarged due to the substitution of $\mathrm{Cu}$ dopants.

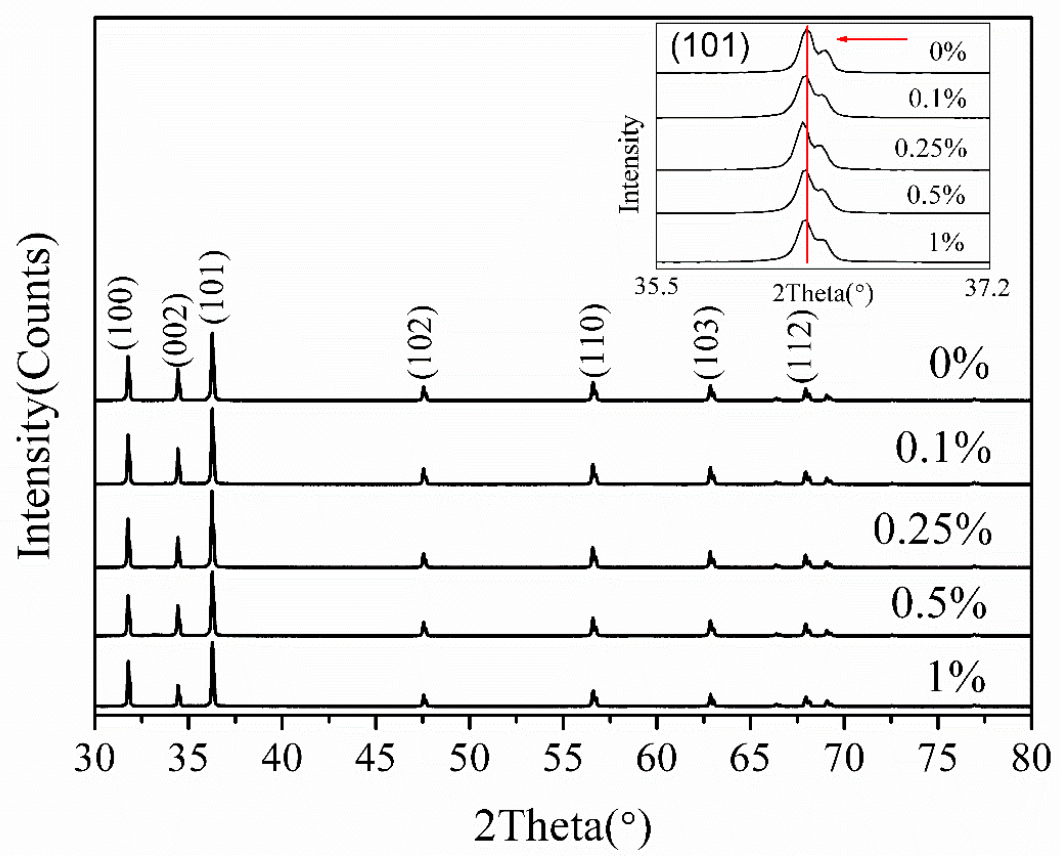

Figure 1. XRD spectra of undoped $\mathrm{ZnO}$ and lightly $\mathrm{Cu}$-doped $\mathrm{ZnO}$ with concentrations of $0.1 \%, 0.25 \%$, $0.5 \%$, and $1 \%$. The inset is the magnified patterns of (101) crystal direction.

To study effects of $\mathrm{Cu}$ concentration on the morphology of lightly Cu-doped ZnO samples, SEM measurement was performed. The results are represented in Figure 2. In the absence of $\mathrm{Cu}$ dopants, the morphologies of the obtained undoped $\mathrm{ZnO}$ nanocrystals were nanoprisms which were not uniform. The diameter and thickness of the nanoprisms were in a range of 310-800 $\mathrm{nm}$ and 200-400 nm, respectively, as shown in Figure 2a. After the addition of Cu dopants with a molar ratio of $0.25 \%$, the nanoprisms were relatively more uniform and the thickness of the nanoprisms increased to a range of 400-1000 nm with the diameter nearly unchanged (Figure 2b). With a further increase of the molar ratio of $\mathrm{Cu}$ dopants to $0.5 \%$, the diameters of the nanoprisms tapered to a range of $250-500 \mathrm{~nm}$ (Figure 2c). When the molar ratio of $\mathrm{Cu}$ dopants reached 1\%, the diameters of the nanoprisms increased to the range of 400-1000 $\mathrm{nm}$ again as shown in Figure $2 \mathrm{~d}$. The SEM results illustrate that the aspect ratio of $\mathrm{ZnO}$ nanocrystals can be modulated by $\mathrm{Cu}$ dopants, because of which the rate of nucleation 
and subsequent growth can be influenced. Similar results were also reported in $\mathrm{Cu}$-doped $\mathrm{ZnO}$ nanocrystals prepared via the vapor transport method [25] and hydrothermal method [18].
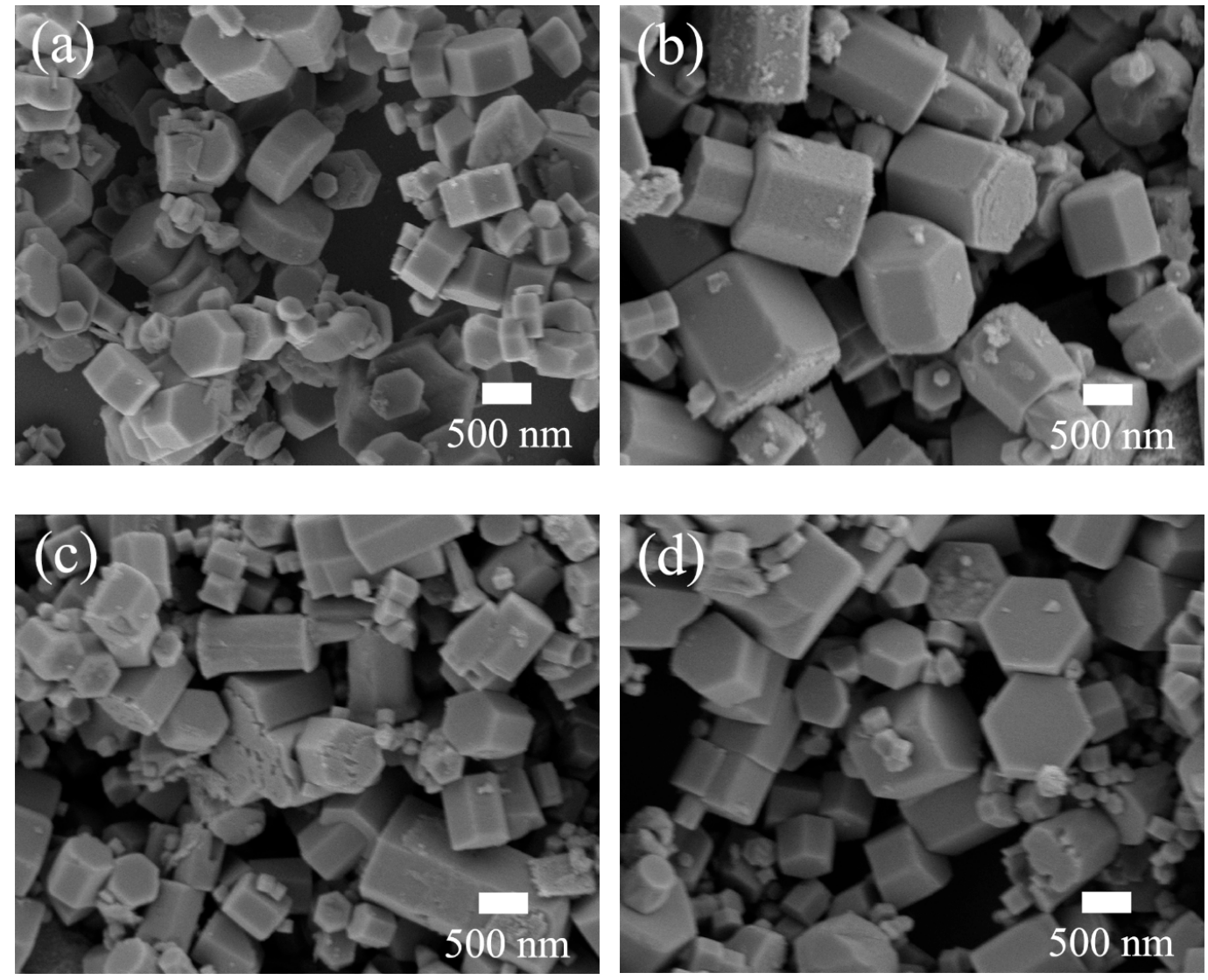

Figure 2. SEM images of undoped $\mathrm{ZnO}$ (a) and lightly $\mathrm{Cu}$-doped $\mathrm{ZnO}$ nanocrystals with different $\mathrm{Cu}$ concentrations: (b) $0.25 \%$, (c) $0.5 \%$, and (d) $1 \%$.

The magnetic properties of these undoped $\mathrm{ZnO}$ and lightly $\mathrm{Cu}$-doped $\mathrm{ZnO}$ nanocrystals were characterized by a Superconducting Quantum Interference Device (SQUID) magnetometer. The field-dependent magnetization $(\mathrm{M}-\mathrm{H})$ curves measured at room temperature in a field range of $0 \pm 5 \mathrm{kOe}$ are shown in Figure 3. It can be seen that the magnetization of all the samples becomes saturated at ca. $2 \mathrm{kOe}$. The variation tendency of the saturated magnetization was depicted in the lower right corner of Figure 3. By increasing the $\mathrm{Cu}$ concentration, the saturated magnetization of $\mathrm{Cu}$-doped $\mathrm{ZnO}$ nanocrystals increased quickly from the value of $1.11 \times 10^{-4}$ to $2.83 \times 10^{-4} \mathrm{emu} / \mathrm{g}(0.25 \mathrm{at} . \%)$ and then decreased linearly to the value of $0.92 \times 10^{-4} \mathrm{emu} / \mathrm{g}(1 \mathrm{at} . \%)$. The saturated magnetizations are comparable with the results reported in the literatures [26,27]. The temperature-dependent magnetization (M-T) were also measured and are shown in Figure S1. In the DMS field, Ram Seshadri pointed out that the magnetic signals of this size $\left(\sim 10^{-6} \mathrm{emu}\right.$, assuming sample mass $\left.10 \mathrm{mg}\right)$ were often misattributed, and time and again shown to be due to impurities from sample holders, oxide phases, etc. [28]. In our case, extrinsic effects such as oxide phases can be ruled out. On one hand, the $\mathrm{Cu}$-doping concentrations in Figure 3 are not more than the threshold (1\%) predicted by Part et al. [19]. On the other hand, if the observed ferromagnetic phenomenon were caused by oxide phases, the trend should be linear with increasing the doping concentration since more oxide phases could be formed by increasing the doping concentration. Even for the $1.5 \% \mathrm{Cu}$-doped sample shown in Figure S2, the ferromagnetic signal also shows a consistent trend observed in our case. To investigate the effect of sample holders, the $\mathrm{M}-\mathrm{H}$ curves of the blank sample holder and those observed after a subtraction of the diamagnetic background were measured and are shown in Figure S3. It can be 
seen that the blank sample holder shows nearly a diamagnetic behavior, and the small ferromagnetic signals were $\sim 10^{-7} \mathrm{emu}$. Compared to our smallest ferromagnetic moment $\left(10^{-4} \mathrm{emu} / \mathrm{g}\right.$, sample mass $\sim 50 \mathrm{mg}$ ), shown in Figure 3, the effect of the sample holder on these samples with Cu concentration not more than $1 \%$ can be ignored. These data demonstrate that the RTFM of lightly Cu-doped ZnO nanocrystals can be indeed modulated by the $\mathrm{Cu}$ dopants.

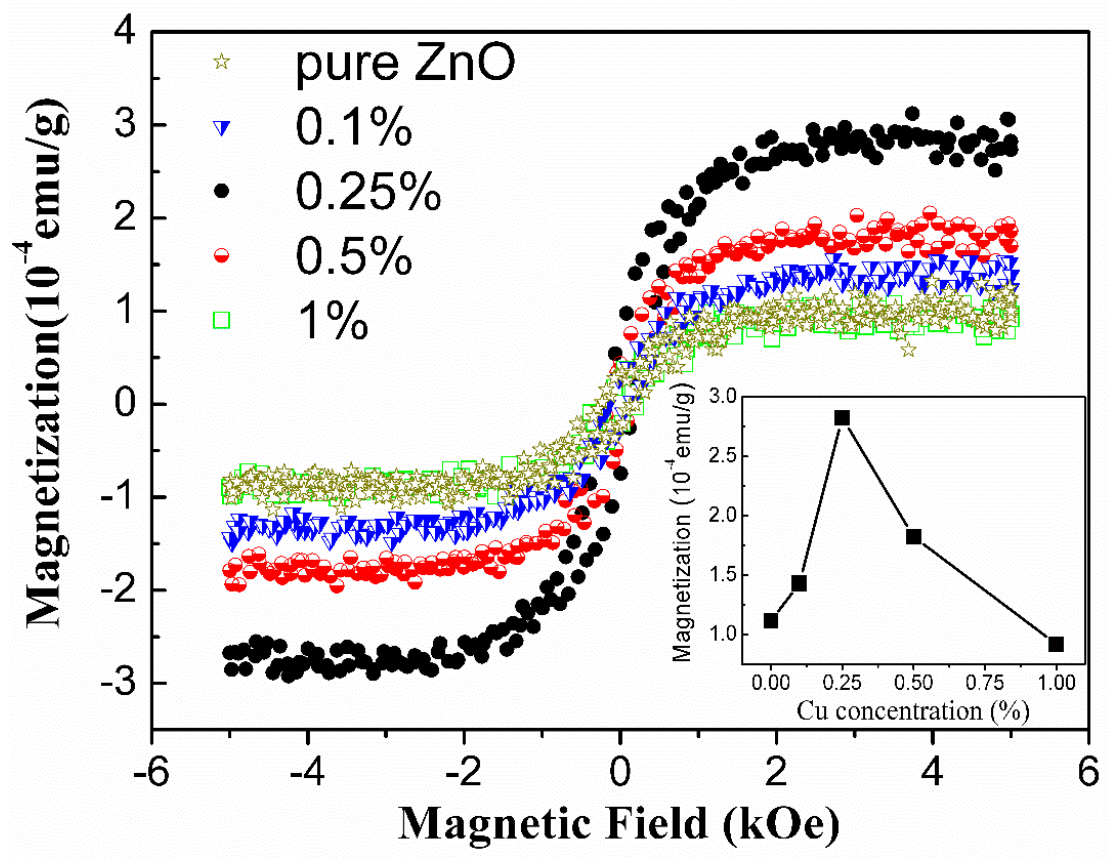

Figure 3. The room temperature field-dependent magnetization $(\mathrm{M}-\mathrm{H})$ curves of undoped and lightly $\mathrm{Cu}$-doped $\mathrm{ZnO}$ nanocrystals with different $\mathrm{Cu}$ concentrations.

Although the real origin of RTFM in Cu-doped $\mathrm{ZnO}$ system is intriguing and not clearly understood, an emerging consensus is coming that ferromagnetism of $\mathrm{Cu}$-doped $\mathrm{ZnO}$ system can be surely induced or mediated by defects in the crystals [29,30]. Therefore, to investigate the defects' distribution in the lightly $\mathrm{Cu}$-doped $\mathrm{ZnO}$ nanocrystals, photoluminescence measurement was carried out. As shown in Figure $4 \mathrm{a}$, all the samples show two distinct emission peaks: a sharp one in the ultraviolet (UV) region and another broad one in the visible region. The former, centered at 388-395 nm, is attributed to free excitonic near-band-edge emission, while the latter is mainly referred to recombination of electrons deeply trapped in oxygen/Zn vacancies and interstitials with photogenerated holes [31]. Much work has been devoted to investigating the origin of the PL in the visible range [32-35]. Generally, the green emission around $527 \mathrm{~nm}$ is mainly attributed to the recombination of electrons trapped in single ionized oxygen vacancies $\left(\mathrm{V}_{\mathrm{O}}{ }^{+}\right)$with photogenerated holes $[32,33]$. The green emission around $575 \mathrm{~nm}$ is ascribed to the doubly ionized oxygen vacancy $\left(\mathrm{V}_{\mathrm{O}^{++}}\right)[32,34]$. The red emission around $657 \mathrm{~nm}$ originates from the intrinsic defects of oxygen interstitials $\left(\mathrm{O}_{\mathrm{i}}\right)$ [36]. To carefully study the above three kinds of defects in $\mathrm{ZnO}: \mathrm{Cu}$ nanocrystals, Gaussian fitting was performed on the visible band in the range of 450-900 nm (Figure $4 \mathrm{~b}$ ). With the $\mathrm{Cu}$ concentration increasing, the concentration of $\mathrm{V}_{\mathrm{O}}{ }^{+}$nearly remained unchanged since the $\mathrm{Cu}$ concentrations were too low to significantly influence the defect contribution (the defect concentration was calculated from the integral area). Many works have proven that RTFM of pure $\mathrm{ZnO}$ and TM-doped $\mathrm{ZnO}$ can be modulated through changing the concentration of oxygen vacancies, especially singly ionized oxygen vacancies by post-annealing $\mathrm{ZnO}$ samples in different atmospheres $[30,31,37]$. However, in this work, RTFM varies remarkably with increasing $\mathrm{Cu}$ concentration in the low doping level ( 1\% at most) while defects' distribution is nearly the same. 

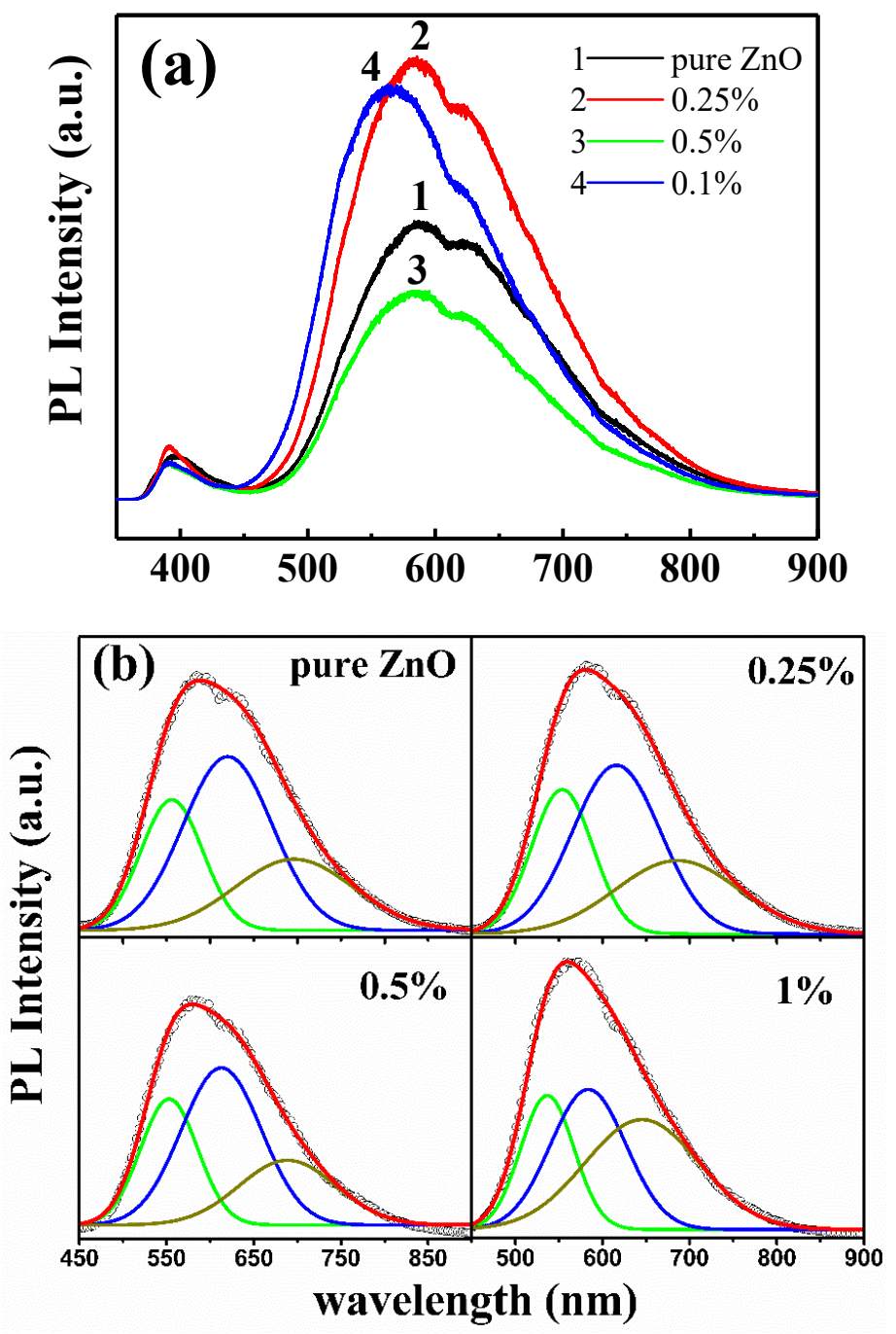

Figure 4. Room temperature (RT) photoluminescence spectra of undoped $\mathrm{ZnO}$ and lightly Cu-doped $\mathrm{ZnO}$ nanocrystals with different concentrations (a) and Gaussian fitted Curves (b) for these experimental spectra.

To further clarify the origin of RTFM, XPS measurement was performed to investigate the bonding characteristics and oxidation states of $\mathrm{Cu}$-doped $\mathrm{ZnO}$ nanocrystals with a molar ratio of $0.25 \%$. The results are represented in Figure 5. The full-range survey scan XPS spectrum in Figure 5a demonstrates that the only elements of the wurtzite-type lightly $\mathrm{Cu}$-doped $\mathrm{ZnO}$ crystals are $\mathrm{Zn}, \mathrm{O}$, and $\mathrm{Cu}$. Figure $5 \mathrm{~b}$ shows the high-resolution $\mathrm{Zn} 2 p$ core-level XPS spectrum. The double symmetrical peaks located at 1022.30 and $1045.31 \mathrm{eV}$ with a difference of $23.01 \mathrm{eV}$ can be ascribed to $\mathrm{Zn} 2 p_{3 / 2}$ and $\mathrm{Zn} 2 p_{1 / 2}$, respectively $[38,39]$, revealing that the oxidation of the $\mathrm{Zn}$ atoms is the $\mathrm{Zn}^{2+}$ chemical state. The broad and asymmetric $\mathrm{O} 1 \mathrm{~s}$ spectrum can be well fitted by three Gaussian curves as depicted in Figure $5 \mathrm{c}$. The lower binding energy peak centered at $530.56 \mathrm{eV}$ is attributed to $\mathrm{O}^{2-}$ ions in wurtzite structure of hexagonal $\mathrm{ZnO}$ [40]. The strongest peak with a higher binding energy centered at $532.30 \mathrm{eV}$ is assigned to $\mathrm{O}^{2-}$ ions in the oxygen-deficient regions within the matrix of $\mathrm{ZnO}$ [39], indicating that plenty of oxygen deficiencies exist on the surface of lightly $\mathrm{Cu}$-doped $\mathrm{ZnO}$ nanocrystals, which is consistent with the result revealed by the PL spectra shown in Figure 4. The highest binding energy peak centered at $532.84 \mathrm{eV}$ can be attributed to the adsorbed oxygen molecular on the surface of the nanocrystals [41]. Figure $5 \mathrm{~d}$ represents the high-resolution XPS spectrum of $\mathrm{Cu} 2 p$ located at $920-970 \mathrm{eV}$. As the $\mathrm{Cu}$-doped level is very low, only the peak of $\mathrm{Cu} 2 p_{3 / 2}$ is well-shaped. The asymmetrical peak of $\mathrm{Cu} 2 p_{3 / 2}$ was also fitted by two Gaussian curves centered at $932.45 \mathrm{eV}$ for $\mathrm{Cu}^{1+}\left(d^{10}\right)$ and $934.22 \mathrm{eV}$ for 
$\mathrm{Cu}^{2+}\left(d^{9}\right)$, respectively $[16,42]$. This obviously shows that the $\mathrm{Cu}$ ions are of two valent states, and the nonmagnetic $\mathrm{Cu}^{1+}\left(d^{10}\right)$ ions account for $86 \%$ of all the $\mathrm{Cu}$ ions. The corresponding narrow-scan spectra of $\mathrm{Cu} 2 p$ in $0.1 \%, 0.5 \%$, and $1 \% \mathrm{Cu}$ doped samples were also measured and are shown in Figure $\mathrm{S} 4$. For $0.5 \%$ and $1 \% \mathrm{Cu}$-doped samples, the nonmagnetic $\mathrm{Cu}^{1+}\left(d^{10}\right)$ ions account for $83 \%$ and $80 \%$, respectively. This result is in coincidence with the XRD results (Figure 1). The inset of Figure 1 indicates that the lattice constants of $\mathrm{ZnO}$ were enlarged by the doped $\mathrm{Cu}$ ions. It is known that the radius of $\mathrm{Cu}^{+}(0.77 \AA)$ ion is bigger than that of $\mathrm{Zn}^{2+}(0.74 \AA)$ and $\mathrm{Cu}^{2+}(0.73 \AA)$ ion [43]. Therefore, it is reasonable to assume that the lattice constants should be enlarged when the $\mathrm{Zn}^{2+}$ ions are substituted by $\mathrm{Cu}^{+}$ions. As is known, all electrons of $\mathrm{Cu}^{+}$ion are paired in the $3 d^{10}$ configuration, and hence, $\mathrm{Cu}^{+}$ions cannot produce a magnetic moment [44]. Therefore, only $\mathrm{Cu}^{2+}$ ions accounting for a small percentage are responsible for the observed RTFM.
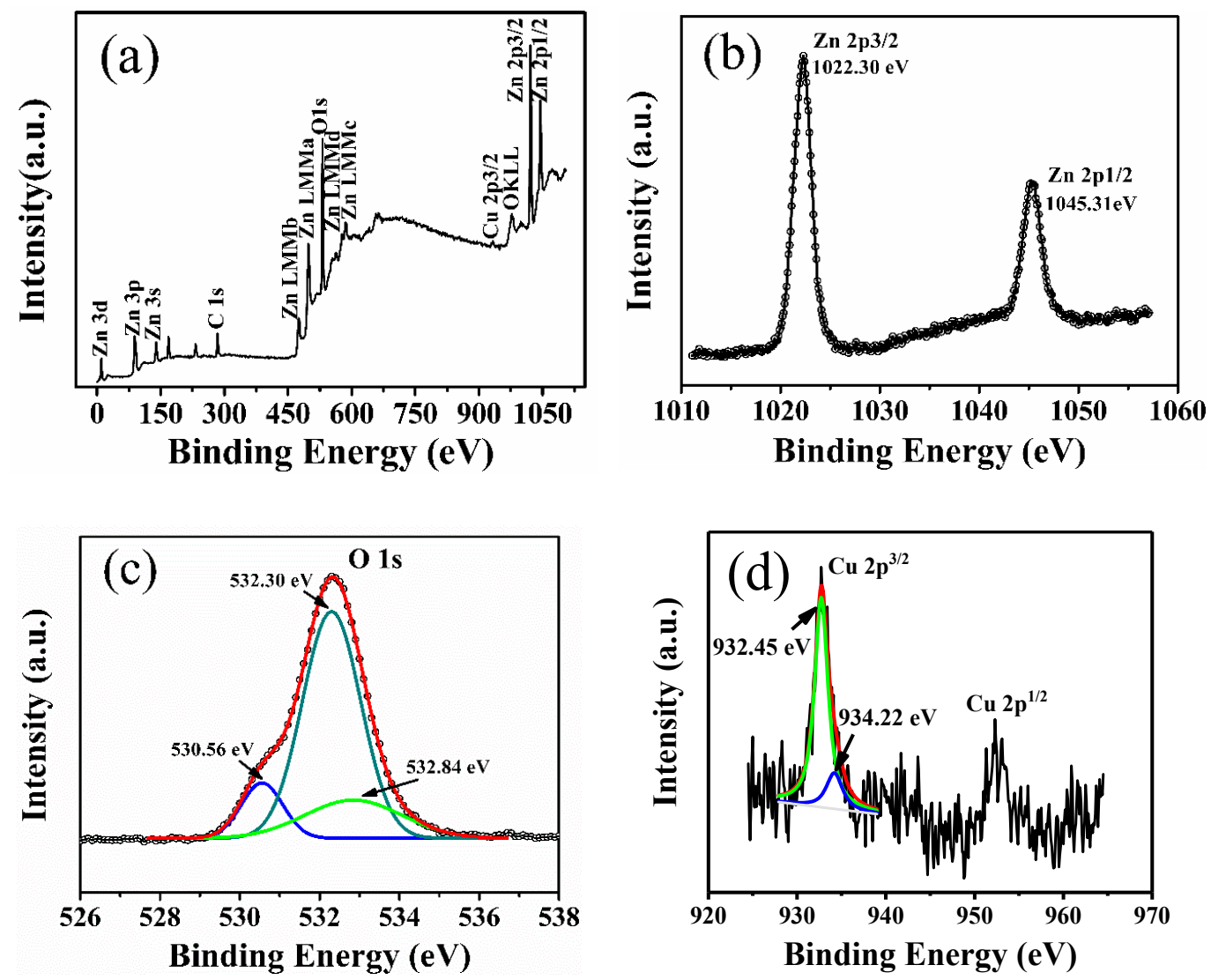

Figure 5. XPS spectra of lightly Cu-doped ZnO (0.25\%) nanocrystals: (a) Wide-scan spectrum; (b-d) the corresponding narrow-scan spectra of $\mathrm{Zn} 2 p, \mathrm{O} 1 s$, and $\mathrm{Cu} 2 p$, respectively. Peak positions are referenced to the adventitious $\mathrm{C} 1 \mathrm{~s}$ peak taken to be at $284.6 \mathrm{eV}$.

Grounded on the above PL observations and the structural properties presented in Figures 1 and 5, we go back to the magnetic properties of the as-prepared samples in Figure 3, which show that the saturated magnetization reached the maximum at the $\mathrm{Cu}$ concentration of $0.25 \mathrm{at} . \%$ and then decreased with $\mathrm{Cu}$ concentration increasing to $1 \%$. The RTFM in undoped $\mathrm{ZnO}$ is generally attributed to oxygen vacancies $\left(\mathrm{V}_{\mathrm{O}}\right)$ which can initiate defect-related hybridization at the Fermi level and establish a long-range ferromagnetic ordering [30,45]. When $\mathrm{Cu}$ ions were incorporated into $\mathrm{Zn}$ sites, Herng et al. pointed out that both oxygen vacancies $\left(\mathrm{V}_{\mathrm{O}}\right)$ and $\mathrm{Cu}$ dopants contributed to RTFM through an indirect double-exchange model, e.g., $\mathrm{Cu}^{+}-\mathrm{V}_{\mathrm{O}}-\mathrm{Cu}^{2+}$ [46]. In this model, $\mathrm{Cu}$ dopants are mediated by the Vo orbital which has a large size with a radius of about 2.25 times the lattice constant. The $\mathrm{Cu}$ ions with different states coupled ferromagnetically by virtual hopping of the extra electron from one ion to 
another via $\mathrm{V}_{\mathrm{O}}$ orbital. Noteworthy, the $\mathrm{Cu}^{2+}$ ions outside the range of Vo vacancies would remain magnetically disordered due to the lack of the indirect double-exchange coupling channel, and only $\mathrm{Cu}^{2+}$ ions residing in the range of Vo vacancies can couple ferromagnetically in this model. This means that only a small fraction of the $\mathrm{Cu}^{2+}$ can contribute to the observed ferromagnetic signal. In our case, the $\mathrm{Cu}$ concentration was very low and the effect of impurity phases can be ruled out. Cu ions were incorporated into Zn sites indicated by XRD results (Figure 1). Further, our XPS measurement reveals that $\mathrm{Cu}$ ions were of two valent states and the proportion of the nonmagnetic $\mathrm{Cu}^{1+}\left(d^{10}\right)$ ions was not less than $80 \%$ of all the $\mathrm{Cu}$ ions in all the $\mathrm{Cu}$ doped samples. This is also consistent with the results $(83 \%)$ reported in [46] that the $\mathrm{Cu}$ dopants in the proximity of Vo orbital would behave more like $d^{10}\left(\mathrm{Cu}^{1+}\right.$-like) when receiving the doped electrons. In this $\mathrm{Cu}$-doped $\mathrm{ZnO}$ system, both oxygen vacancies and $\mathrm{Cu}$ dopants can contribute to RTFM through an indirect double-exchange model. However, our PL results demonstrate that the oxygen deficiency distributions remained nearly unchanged with increasing $\mathrm{Cu}$ concentration under low doping level. Therefore, it can be concluded that $\mathrm{Cu}$ dopants and their coupling with oxygen deficiencies are responsible for the observed phenomenon. Based on the above analysis, a possible mechanism for the magnetic moment evolution with increasing $\mathrm{Cu}$ concentration is suggested, as illustrated in Figure 6. At the initial state, the doping of $\mathrm{Cu}^{2+}$ ions can couple with $\mathrm{Vo}^{+}$ferromagnetically through indirect double-exchange model and enhance the long-range ferromagnetic ordering since magnetic $\mathrm{Cu}^{2+}$ ions were introduced into $\mathrm{ZnO}$ wurtzite structure (Figure 6a). With increasing $\mathrm{Cu}$ dopant concentration, the distance between two $\mathrm{Cu}$ ions becomes shorter and shorter. Feng et al. found that antiferromagnetic configuration was favored over the ferromagnetic one when the distance between $\mathrm{Cu}$ ions was in a certain range based on the B3LYP hybrid density functional [47]. Therefore, it is reasonable to propose that with further increasing $\mathrm{Cu}$ concentration beyond $0.25 \%$ continuously at low doping level ( $1 \%$ at most), the distance between $\mathrm{Cu}$ ions became shorter and the antiferromagnetic couples were dominated by the $\mathrm{Cu}$ ions generated, resulting in the declination of the magnetization (Figure 6b). This antiferromagnetic phenomenon was also reported in other TM-doped $\mathrm{ZnO}$ systems, such as Co [48], Ni [49], and Mn [50,51]. Further work needs to be done to study the coupling behavior between the magnetic dopants and defects on the ferromagnetism of $\mathrm{Cu}$-doped $\mathrm{ZnO}$ system at low doping level.

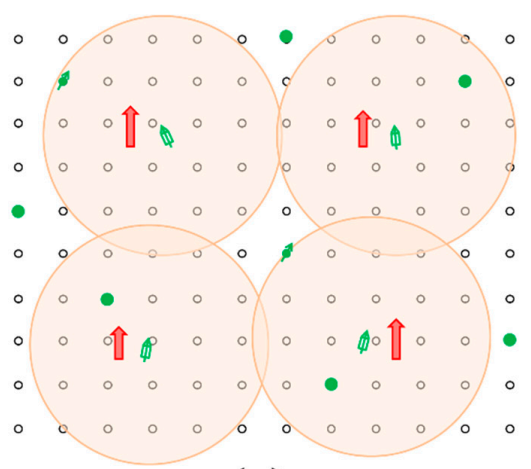

(a)

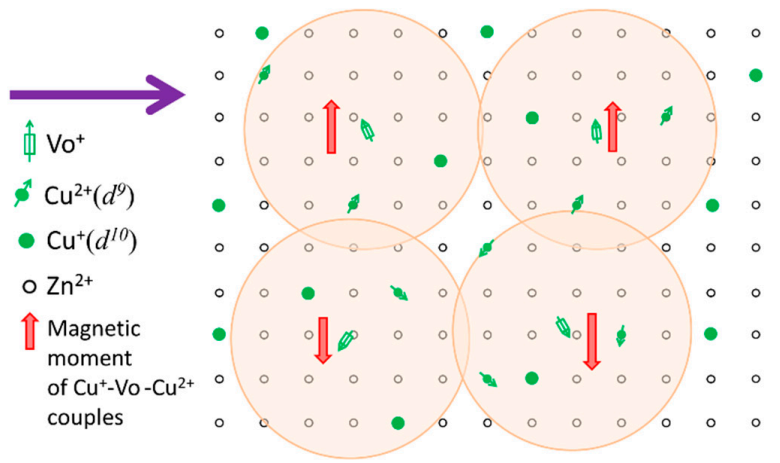

(b)

Figure 6. The schematic illustration of the magnetic moment evolution with increasing $\mathrm{Cu}$ concentration of lightly $\mathrm{Cu}$-doped $\mathrm{ZnO}$ : (a) ferromagnetism of $\mathrm{Cu}^{+}-\mathrm{V}_{\mathrm{O}}-\mathrm{Cu}^{2+}$ couples through an indirect double-exchange model; (b) antiferromagnetic $\mathrm{Cu}^{+}-\mathrm{V}_{\mathrm{O}}-\mathrm{Cu}^{2+}$ couples dominated by $\mathrm{Cu}$ ions. The orange circle represents the oxygen vacancy orbital.

\section{Conclusions}

We have found that room temperature ferromagnetism observed in lightly $\mathrm{Cu}$-doped $\mathrm{ZnO}$ nanocrystals could be modulated by changing the concentration of $\mathrm{Cu}$ dopants. Combining the XRD and XPS analysis, $\mathrm{Cu}^{2+}$ and $\mathrm{Cu}^{+}$ions were successfully incorporated into $\mathrm{Zn}$ sites of $\mathrm{ZnO}$ wurtzite structure. Oxygen deficiencies were abundant in the lightly $\mathrm{Cu}$-doped $\mathrm{ZnO}$ nanocrystals, and the 
distribution of these defects was nearly unchanged, as revealed by XPS and PL measurements. The Cu dopants are responsible for the variation of room temperature ferromagnetism. The results suggest that $\mathrm{Cu}$ ions at an ultralow concentration can enhance long-range ferromagnetic ordering but may generate antiferromagnetic " $\mathrm{Cu}^{+}-\mathrm{Vo}-\mathrm{Cu}^{2+"}$ couples even at a very low $\mathrm{Cu}$-doping concentration.

Supplementary Materials: The following are available online at http://www.mdpi.com/2079-4991/10/8/1578/s1, Figure S1: The M-T curves of the $0.25 \%$ Cu doped ZnO sample, Figure S2: The M-H curves of the 1.5\% Cu doped $\mathrm{ZnO}$ sample and those after a subtraction of the diamagnetic background, Figure S3: The M-H curves of the blank sample holder and those after a subtraction of the diamagnetic background, Figure S4: The corresponding narrow-scan spectra of $\mathrm{Cu} 2 p$ for the $0.1 \%, 0.25 \%, 0.5 \%$ and $1 \% \mathrm{Cu}$ doped samples.

Author Contributions: Data curation, N.Q., M.T. and H.S.; Formal analysis, X.Z. and J.T. (Junlong Tian); Investigation, W.X.; Methodology, W.Z.; Validation, J.T. (Jiahua Tao); Visualization, M.T.; Writing一review \& editing, Z.W. All authors have read and agreed to the published version of the manuscript.

Funding: This research was funded by the National Natural Science Foundation of China, grant number 61604002, Henan Key Technology Research and Development, grant number 172102210166, Henan College Key Research Project, grant number 20A140002 and 19B140001, Open foundation of Guangxi Key Laboratory of Processing for Non-ferrous Metals and Featured Materials, Guangxi University, grant number 2020GXYSOF, CAS Key Laboratory of Nano-Bio Interface, grant number 20YZ08, and College students Innovation Fund of Anyang Normal University, grant number X2020104790107. The APC was funded by the National Natural Science Foundation of China, Grant number 61604002.

Conflicts of Interest: The authors declare no conflict of interest. The funders had no role in the design of the study, in the collection, analyses, or interpretation of data, in the writing of the manuscript, or in the decision to publish the results.

\section{References}

1. Zhang, H.; Wang, N.; Wang, S.; Zhang, Y. Effect of doping 3d transition metal (Fe, Co, and Ni) on the electronic, magnetic and optical properties of pentagonal $\mathrm{ZnO}_{2}$ monolayer. Phys. E Low Dimens. Syst. Nanostructures 2020, 117, 113806. [CrossRef]

2. Singh, P.; Kumar, R.; Singh, R.K. Progress on transition metal-doped ZnO nanoparticles and its application. Ind. Eng. Chem. Res. 2019, 58, 17130-17163. [CrossRef]

3. Pan, H.; Zhang, Y.; Hu, Y.; Xie, H. Effect of cobalt doping on optical, magnetic and photocatalytic properties of ZnO nanoparticles. Optik 2020, 208, 164560. [CrossRef]

4. More, D.; Phadnis, C.; Basu, S.; Pathak, A.; Dubenko, I.; Ali, N.; Jha, S.; Bhattachryya, D.; Mahamuni, S. Correlation of structural and magnetic properties of Ni-doped $\mathrm{ZnO}$ nanocrystals. J. Phys. D Appl. Phys. 2014, 47, 045308. [CrossRef]

5. Kittilstved, K.R.; Norberg, N.S.; Gamelin, D.R. Chemical manipulation of high $\mathrm{T}_{\mathrm{C}}$ ferromagnetism in $\mathrm{ZnO}$ diluted magnetic semiconductors. Phys. Rev. Lett. 2005, 94, 147209. [CrossRef]

6. Marquina, J.; Quintero, E.; Ruette, F.; Bentarcurt, Y. Theoretical study of Mn doping effects and O or Zn vacancies on the magnetic properties in wurtzite ZnO. Chin. J. Phys. 2020, 63, 63-69. [CrossRef]

7. Kayani, Z.N.; Iram, S.; Rafi, R.; Riaz, S.; Naseem, S. Effect of Cu doping on the structural, magnetic and optical properties of $\mathrm{ZnO}$ thin films. Appl. Phys. A 2018, 124, 468. [CrossRef]

8. Malaidurai, M.; Santosh Kumar, B.; Thangavel, R. Spin polarized carrier injection driven magneto-optical Kerr effect in Cr-doped ZnO nanorods. Phys. Lett. A 2019, 383, 2988-2992. [CrossRef]

9. Lardé, R.; Talbot, E.; Pareige, P.; Bieber, H.; Schmerber, G.; Colis, S.; Pierron-Bohnes, V.; Dinia, A. Evidence of superparamagnetic Co clusters in pulsed laser deposition-grown $\mathrm{Zn}_{0.9} \mathrm{Co}_{0.1} \mathrm{O}$ thin films using atom probe tomography. J. Am. Chem. Soc. 2011, 133, 1451-1458. [CrossRef]

10. Bang, J.; Kim, Y.-S.; Park, C.H.; Gao, F.; Zhang, S.B. Understanding the presence of vacancy clusters in ZnO from a kinetic perspective. Appl. Phys. Lett. 2014, 104, 252101. [CrossRef]

11. Chiou, J.W.; Chang, S.Y.; Huang, W.H.; Chen, Y.T.; Hsu, C.W.; Hu, Y.M.; Chen, J.M.; Chen, C.H.; Kumar, K.; Guo, J.H. The characterization of $\mathrm{Cr}$ secondary oxide phases in $\mathrm{ZnO}$ films studied by X-ray spectroscopy and photoemission spectroscopy. Appl. Surf. Sci. 2011, 257, 4863-4866. [CrossRef]

12. Gao, D.; Zhang, Z.; Li, Y.; Xia, B.; Shi, S.; Xue, D. Abnormal room temperature ferromagnetism in CuO-ZnO heterostructures: Interface related or not? Chem. Commun. 2015, 51, 1151-1153. [CrossRef] [PubMed] 
13. Heinhold, R.; Kim, H.-S.; Schmidt, F.; Von Wenckstern, H.; Grundmann, M.; Mendelsberg, R.J.; Reeves, R.J.; Durbin, S.M.; Allen, M.W. Optical and defect properties of hydrothermal ZnO with low lithium contamination. Appl. Phys. Lett. 2012, 101, 062105. [CrossRef]

14. Altıntaş Yıldırım, Ö.; Durucan, C. Room temperature synthesis of $\mathrm{Cu}$ incorporated $\mathrm{ZnO}$ nanoparticles with room temperature ferromagnetic activity: Structural, optical and magnetic characterization. Ceram. Int. 2016, 42, 3229-3238. [CrossRef]

15. Verma, K.C.; Kotnala, R.K. Understanding lattice defects to influence ferromagnetic order of ZnO nanoparticles by Ni, Cu, Ce ions. J. Solid State Chem. 2017, 246, 150-159. [CrossRef]

16. Liu, H.; Wang, Y.; Wu, J.; Zhang, G.; Yan, Y. Oxygen vacancy assisted multiferroic property of Cu doped ZnO films. Phys. Chem. Chem. Phys. 2015, 17, 9098-9105. [CrossRef]

17. Younas, M.; Xu, C.; Arshad, M.; Ho, L.P.; Zhou, S.; Azad, F.; Akhtar, M.J.; Su, S.; Azeem, W.; Ling, F.C.C. Reversible tuning of ferromagnetism and resistive switching in $\mathrm{ZnO} / \mathrm{Cu}$ thin films. ACS Omega 2017, 2, 8810-8817. [CrossRef]

18. Sharma, P.K.; Dutta, R.K.; Pandey, A.C. Doping dependent room-temperature ferromagnetism and structural properties of dilute magnetic semiconductor $\mathrm{ZnO}: \mathrm{Cu}^{2+}$ nanorods. J. Magn. Magn. Mater. 2009, 321, 4001-4005. [CrossRef]

19. Park, M.S.; Min, B.I. Ferromagnetism in $\mathrm{ZnO}$ codoped with transition metals: $\mathrm{Zn}_{1-\mathrm{x}}(\mathrm{FeCo})_{\mathrm{x}} \mathrm{O}$ and $\mathrm{Zn}_{1-\mathrm{x}}(\mathrm{FeCu})_{\mathrm{x}} \mathrm{O}$. Phys. Rev. B 2003, 68, 224436. [CrossRef]

20. Wang, X.; Xu, J.B.; Cheung, W.Y.; An, J.; Ke, N. Aggregation-based growth and magnetic properties of inhomogeneous Cu-doped ZnO nanocrystals. Appl. Phys. Lett. 2007, 90, 212502. [CrossRef]

21. Hou, X.; Sun, H.; Liu, L.; Jia, X.; Liu, H. Unexpected large room-temperature ferromagnetism in porous $\mathrm{Cu}_{2} \mathrm{O}$ thin films. J. Magn. Magn. Mater. 2015, 382, 20-25. [CrossRef]

22. Wei, M.; Braddon, N.; Zhi, D.; Midgley, P.A.; Chen, S.K.; Blamire, M.G.; MacManus-Driscoll, J.L. Room temperature ferromagnetism in bulk Mn-Doped $\mathrm{Cu}_{2} \mathrm{O}$. Appl. Phys. Lett. 2005, 86, 072514. [CrossRef]

23. Yu, C.; Mutlu, S.; Selvaganapathy, P.; Mastrangelo, C.H.; Svec, F.; Fréchet, J.M.J. Flow control valves for analytical microfluidic chips without mechanical parts based on thermally responsive monolithic polymers. Anal. Chem. 2003, 75, 1958-1961. [CrossRef] [PubMed]

24. Standards, J.C.O.P.D. Powder Diffraction File (PDF); International Centre for Diffraction Data: Newton Square, PA, USA, 2004.

25. Mohan, R.; Krishnamoorthy, K.; Kim, S.-J. Enhanced photocatalytic activity of Cu-doped ZnO nanorods. Solid State Commun. 2012, 152, 375-380. [CrossRef]

26. Ghosh, B.; Sardar, M.; Banerjee, S. Destruction of ferromagnetism in Cu-doped ZnO upon thermal annealing: Role of oxygen vacancy. J. Phys. D Appl. Phys. 2013, 46, 135001. [CrossRef]

27. Xue, X.; Liu, L.; Wang, Z.; Wu, Y. Room-temperature ferromagnetism in hydrogenated ZnO nanoparticles. J. Appl. Phys. 2014, 115, 033902. [CrossRef]

28. Seshadri, R. Zinc oxide-based diluted magnetic semiconductors. Curr. Opin. Solid State Mater. Sci. $2005,9,7$. [CrossRef]

29. Hu, L.; Zhu, L.; He, H.; Zhang, L.; Ye, Z. Acceptor defect-participating magnetic exchange in ZnO:Cu nanocrystalline film: Defect structure evolution, $\mathrm{Cu}-\mathrm{N}$ synergetic role and magnetic control. J. Mater. Chem. C 2015, 3, 1330-1346. [CrossRef]

30. Liu, W.; Li, W.; Hu, Z.; Tang, Z.; Tang, X. Effect of oxygen defects on ferromagnetic of undoped ZnO. J. Appl. Phys. 2011, 110, 013901. [CrossRef]

31. Liu, W.; Tang, X.; Tang, Z. Effect of oxygen defects on ferromagnetism of Mn doped ZnO. J. Appl. Phys. 2013, 114, 123911. [CrossRef]

32. Vanheusden, K.; Seager, C.H.; Warren, W.L.; Tallant, D.R.; Voigt, J.A. Correlation between photoluminescence and oxygen vacancies in ZnO phosphors. Appl. Phys. Lett. 1996, 68, 403-405. [CrossRef]

33. Lin, C.Y.; Wang, W.H.; Lee, C.-S.; Sun, K.W.; Suen, Y.W. Magnetophotoluminescence properties of Co-doped ZnO nanorods. Appl. Phys. Lett. 2009, 94, 151909. [CrossRef]

34. Van Dijken, A.; Meulenkamp, E.A.; Vanmaekelbergh, D.; Meijerink, A. The luminescence of nanocrystalline $\mathrm{ZnO}$ particles: The mechanism of the ultraviolet and visible emission. J. Lumin. 2000, 87-89, 454-456. [CrossRef] 
35. Tam, K.H.; Cheung, C.K.; Leung, Y.H.; Djurišić, A.B.; Ling, C.C.; Beling, C.D.; Fung, S.; Kwok, W.M.; Chan, W.K.; Phillips, D.L.; et al. Defects in ZnO nanorods prepared by a hydrothermal method. J. Phys. Chem. B 2006, 110, 20865-20871. [CrossRef]

36. Wu, X.L.; Siu, G.G.; Fu, C.L.; Ong, H.C. Photoluminescence and cathodoluminescence studies of stoichiometric and oxygen-deficient ZnO films. Appl. Phys. Lett. 2001, 78, 2285-2287. [CrossRef]

37. Liu, W.; Tang, X.; Tang, Z.; Chu, F.; Zeng, T.; Tang, N. Role of oxygen defects in magnetic property of Cu doped ZnO. J. Alloy. Compd. 2014, 615, 740-744. [CrossRef]

38. Moulder, J.F.; Stickle, W.F.; Sobol, P.E.; Bomben, K.D. (Eds.) Handbook of X-ray Photoelectron Spectroscopy; ULVAC-PHI: Chigasaki, Japan, 1992.

39. Aljawfi, R.N.; Mollah, S. Properties of Co/Ni codoped ZnO based nanocrystalline DMS. J. Magn. Magn. Mater. 2011, 323, 3126-3132. [CrossRef]

40. Chen, M.; Wang, X.; Yu, Y.H.; Pei, Z.L.; Bai, X.D.; Sun, C.; Huang, R.F.; Wen, L.S. X-ray photoelectron spectroscopy and auger electron spectroscopy studies of Al-doped ZnO films. Appl. Surf. Sci. 2000, 158, 134-140. [CrossRef]

41. Koshy, O.; Khadar, M.A. Superparamagnetism in undoped ZnO nanorods. Appl. Surf. Sci. 2015, 346, 528-533. [CrossRef]

42. Xu, D.H.; Shen, W.Z. Cu-doped ZnO hemispherical shell structures: Synthesis and room-temperature ferromagnetism properties. J. Phys. Chem. C 2012, 116, 13368-13373. [CrossRef]

43. Hsu, C.-L.; Gao, Y.-D.; Chen, Y.-S.; Hsueh, T.-J. Vertical p-type Cu-doped ZnO/n-type ZnO homojunction nanowire-based ultraviolet photodetector by the furnace system with hotwire assistance. ACS Appl. Mater. Interfaces 2014, 6, 4277-4285. [CrossRef]

44. Chakraborti, D.; Narayan, J.; Prater, J.T. Room temperature ferromagnetism in $\mathrm{Zn}_{1-\mathrm{x}} \mathrm{Cu}_{\mathrm{x}} \mathrm{O}$ thin films. Appl. Phys. Lett. 2007, 90, 062504. [CrossRef]

45. Coey, J.M.D.; Venkatesan, M.; Fitzgerald, C.B. Donor impurity band exchange in dilute ferromagnetic oxides. Nat. Mater. 2005, 4, 173-179. [CrossRef]

46. Herng, T.S.; Qi, D.C.; Berlijn, T.; Yi, J.B.; Yang, K.S.; Dai, Y.; Feng, Y.P.; Santoso, I.; Sánchez-Hanke, C.; Gao, X.Y.; et al. Room-temperature ferromagnetism of Cu-doped $\mathrm{ZnO}$ films probed by soft X-ray magnetic circular dichroism. Phys. Rev. Lett. 2010, 105, 207201. [CrossRef]

47. Feng, X. Electronic structures and ferromagnetism of $\mathrm{Cu}$ - and Mn-doped ZnO. J. Phys. Condens. Matter 2004, 16, 4251. [CrossRef]

48. Lee, E.-C.; Chang, K.J. Ferromagnetic versus antiferromagnetic interaction in Co-doped ZnO. Phys. Rev. B 2004, 69, 085205. [CrossRef]

49. Yadav, H.K.; Sreenivas, K.; Gupta, V.; Katiyar, R.S. Structural studies and Raman spectroscopy of forbidden zone boundary phonons in Ni-doped ZnO ceramics. J. Raman Spectrosc. 2009, 40, 381-386. [CrossRef]

50. Lawes, G.; Risbud, A.S.; Ramirez, A.P.; Seshadri, R. Absence of ferromagnetism in Co and Mn substituted polycrystalline ZnO. Phys. Rev. B 2005, 71, 045201. [CrossRef]

51. Zhang, K.-C.; Li, Y.-F.; Liu, Y.; Zhu, Y. Density-functional study on the ferromagnetism of (Mn, Na)-codoped ZnO. Phys. B Condens. Matter 2014, 451, 43-47. [CrossRef]

(C) 2020 by the authors. Licensee MDPI, Basel, Switzerland. This article is an open access article distributed under the terms and conditions of the Creative Commons Attribution (CC BY) license (http://creativecommons.org/licenses/by/4.0/). 